\title{
PSEUDARTHROSIS OF THE TUBERCLE OF THE SCAPHOID BONE IN IMMATURE SKELETON: CASE REPORT
}

Eduardo Amaral Gomes' ${ }^{1}$, Felipe Armanelli ${ }^{2}$, Gustavo Augusto Matos Saliba ${ }^{3}$

\section{ABSTRACT}

The aim of this study was to present a case report on pseudarthrosis of the scaphoid tubercle, a pathological condition that affects the young and active population. This entity often develops as a result of failure to make an early diagnosis and a late start to treatment. This report describes the case of a 15-year-old patient with a history of a neglected fracture of the scaphoid tubercle that occurred one year earlier and evolved to pseudarthrosis of the tubercle, which is an unusual location for this type of complication. The diagnosis was made from the clinical history and radiographic examination. The treatment was undertaken in accordance with the Matti-Russe technique, by means of a volar route, thus avoiding injury to the scaphoid vascularization, with good clinical and radiographic evolution. Pseudarthrosis of the scaphoid tubercle is a rare condition resulting from a fracture in an unusual location in the scaphoid bone, and it is important because it affects the young and active population. The correct diagnosis is only rarely made by radiologists or surgeons at the time of the fracture, because of failure to recognize this entity. This mistake delays and causes difficulty in treatments for the complications resulting from this kind of fracture. Therefore, it is essential to include this condition in differential diagnoses in order to avoid mistaken conduct. The treatment chosen was shown to be an effective option in this specific case.

Keywords - Scaphoid Bone; Pseudarthrosis/therapy; Pseudarthrosis/complications; Pseudarthrosis/surgery; Bone Transplantation; Adolescent

\section{INTRODUCTION}

The scaphoid is the carpal bone that is most susceptible to fractures ${ }^{(1-4)}$. After fractures of the distal radius, this is the most frequent site of wrist fractures. However, it is often diagnosed at a late stage, such that the prognosis for consolidation is worsened.

The scaphoid is formed by five joint surfaces and connects the proximal and distal rows of the carpus ${ }^{(1,4)}$. Its blood irrigation is poor and comes from the radial artery through two main systems: dorsal, through the dorsal carpal branch; and volar, through the superficial branch, which penetrates the bone by means of its tubercle. Thus, the vascularization is rich in the distal two thirds and poor in the proximal center ${ }^{(1)}$.

Falling involving injury with the wrist hyperex- tended $\left(90^{\circ}\right.$ or more), in association with radial deviation is the classical trauma mechanism for scaphoid lesions $^{(1,2)}$. The fracture site is determined by the degree of radial deviation of the wrist at the time of the trauma. In adults, the most frequent site is the scaphoid belt (65\%), followed by the proximal center $(15 \%)$, distal body (10\%), tuberosity (8\%) and distal joint surface $(2 \%)^{(1)}$.

In children, the most frequently fractured site is the distal center, followed by the scaphoid belt. Fractures of the proximal center are exceptional ${ }^{(3)}$.

This fracture pattern follows the retrograde vascularization pattern, which also guides the direction of bone ossification, which is completed between the ages of four and five years ${ }^{(3)}$.

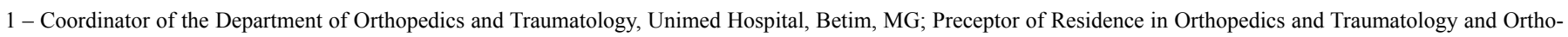
pedist at the "Governor Israel Pinheiro" General Hospital (IPSEMG), Belo Horizonte, MG, Brazil.

2 - Orthopedist at the São José University Hospital, School of Medical Sciences of Minas Gerais, Belo Horizonte, MG, Brazil.

3 - General Surgeon at the Unimed Hospital, Betim, MG; Resident in Plastic Surgery at the Felício Rocho Hospital, Belo Horizonte, MG, Brazil.

Work performed at the Unimed Hospital, Betim, MG, Brazil.

Correspondence: Rua Dr. Hackett 29, Castelinho, 32510-400 Betim, MG. E-mail: edagomes@uai.com.br

Work received for publication: May 26, 2011; accepted for publication: July 20, 2011.

The authors declare that there was no conflict of interest in conducting this work 
Although scaphoid fractures are the most frequent type among children's carpal bones, their incidence is low and much below the incidence of fractures of the distal radius, which account for almost half of the fractures in children. Thus, even in cases in which a scaphoid fracture is confirmed, concomitant fracturing of the distal radius should be investigated ${ }^{(3)}$.

The peak incidence occurs around 15 years of age. Occurrences during the first decade of life are virtually nonexistent ${ }^{(3)}$. All the cases occur in young men, because of the greater physical activity in this age group, which exposes these individuals to frequent traumatic events.

The particular anatomy of the scaphoid predisposes it to delayed consolidation and pseudarthrosis, because it is jointed to four of the seven carpal bones. In addition to the vascularization pattern, other factors contribute towards non-consolidation of fractures: high-energy trauma, comminution, aggressive surgical manipulation, non-adherence to treatment and failure to initially diagnose the facture ${ }^{(1,4)}$.

Pseudarthrosis usually presents with pain, weakness and diminished range of motion (ROM) of the wrist. However, it may be asymptomatic and may be diagnosed by chance during a radiographic examination ${ }^{(1,2,4)}$.

Although some authors have proposed conservative treatment, there is now a consensus that the treatment of choice is surgical, even in asymptomatic cases, since the aim of surgery is not only to improve strength and reduce pain, but also to present occurrences of arthrotic degeneration later on ${ }^{(1,2,4)}$.

The classical preferred technique is the one proposed by Matti and Russe ${ }^{(1)}$. If there is any carpal instability, the Fisk-Fernandez grafting method is indicated $^{(1)}$. Vascularized bone grafts (Zaidemberg and
Mathoulin) have been gaining space within medical practice, but today they are best indicated for cases of surgical revision in which the graft from the iliac crest was ineffective ${ }^{(1,4)}$.

The objective of the present study was to present a report on a case of pseudarthrosis of the scaphoid tubercle, a pathological condition that affects young and active populations and which often develops as a result of failure to diagnose the case early on and a late start to treatment.

\section{CASE REPORT}

The patient was a 15-year-old boy who came to the outpatient clinic with a complaint of low-intensity intermittent pain located in the radial margin and diminished grip strength in the left wrist. His mother provided the information that one year earlier, the patient had suffered a fall from a bicycle, with trauma to that wrist, which had been treated with plaster-cast immobilization. At that time, the boy did not adhere to the treatment: he removed his immobilization and did not attend the outpatient return visits.

The physical examination showed a poor condition, with pain on palpation of the scaphoid tubercle and slight diminution of grip strength, in comparison with the contralateral wrist. No edema, deformities or diminution of ROM were noted.

A radiograph showed an extra-articular fracture of the scaphoid tubercle with a displacement of $3 \mathrm{~mm}$ and signs of bone reabsorption on the borders, thus leading to a diagnosis of pseudarthrosis of the border of the scaphoid (Figure 1).

Surgical treatment was proposed, and open reduction
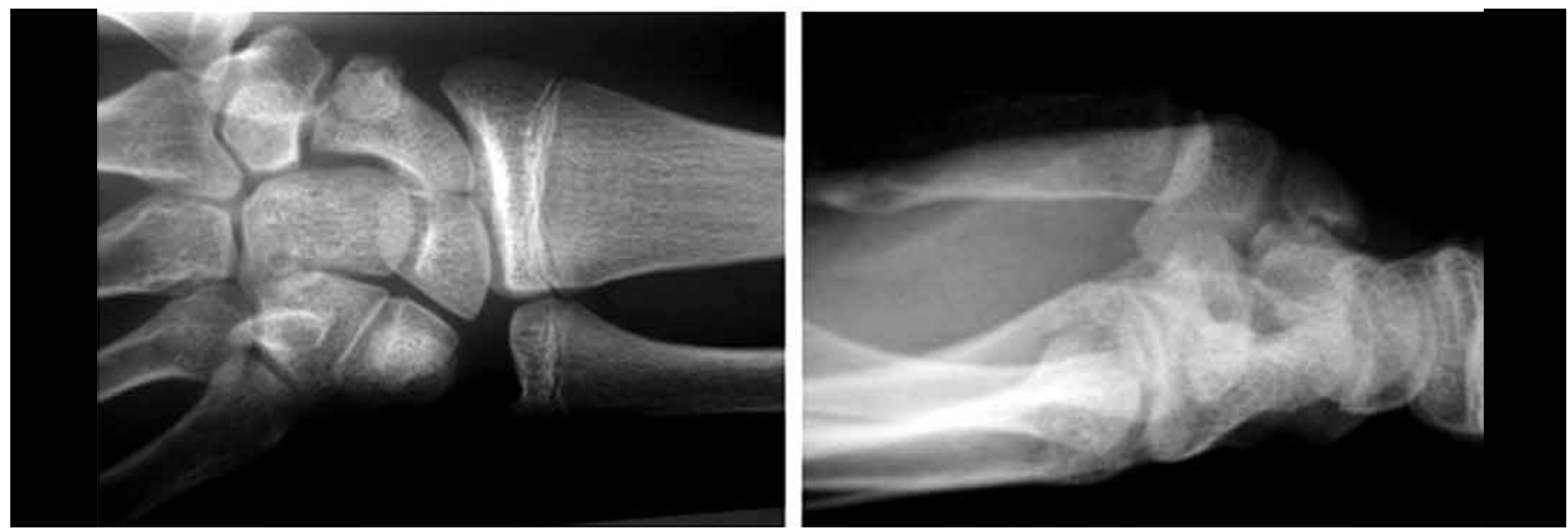

Figure 1 - Pseudarthrosis of the tubercle of the scaphoid, deviated to the left. Note open growth plate on the distal radius and ulna 
and internal fixation were performed. A volar access was constructed, with curettage of the focus of the pseudarthrosis and bone grafting using the Matti-Russe method (harvesting a graft from the ipsilateral iliac crest), and fixation using two Kirschner wires (Figure 2).

After the operation, a plaster splint that included the thumb was kept in place for two weeks. After removal of the stitches, a short plaster cast was placed and was kept in place for six weeks. The Kirschner wires were removed as an outpatient procedure in the $12^{\text {th }}$ week after the operation, after bone consolidation had been confirmed, and the patient was referred for rehabilitation.

A few days after the operation, it was noted that the patient presented complete ROM without pain. One year after the operation, the patient presented normal grip strength. Four years after the operation, a final review was made. The patient (now 19 years of age)
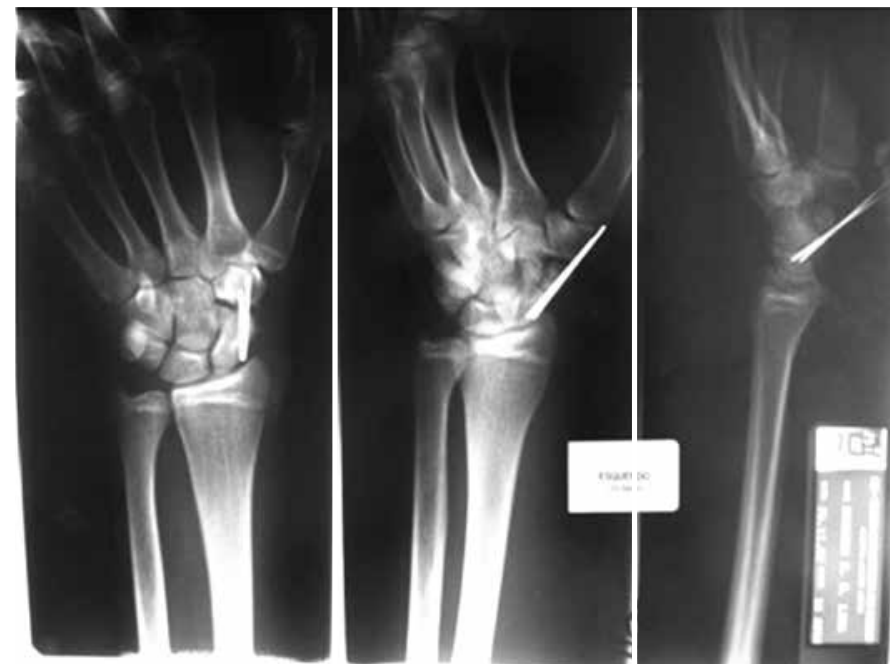

Figure 2 - Fixation using Kirschner wires.
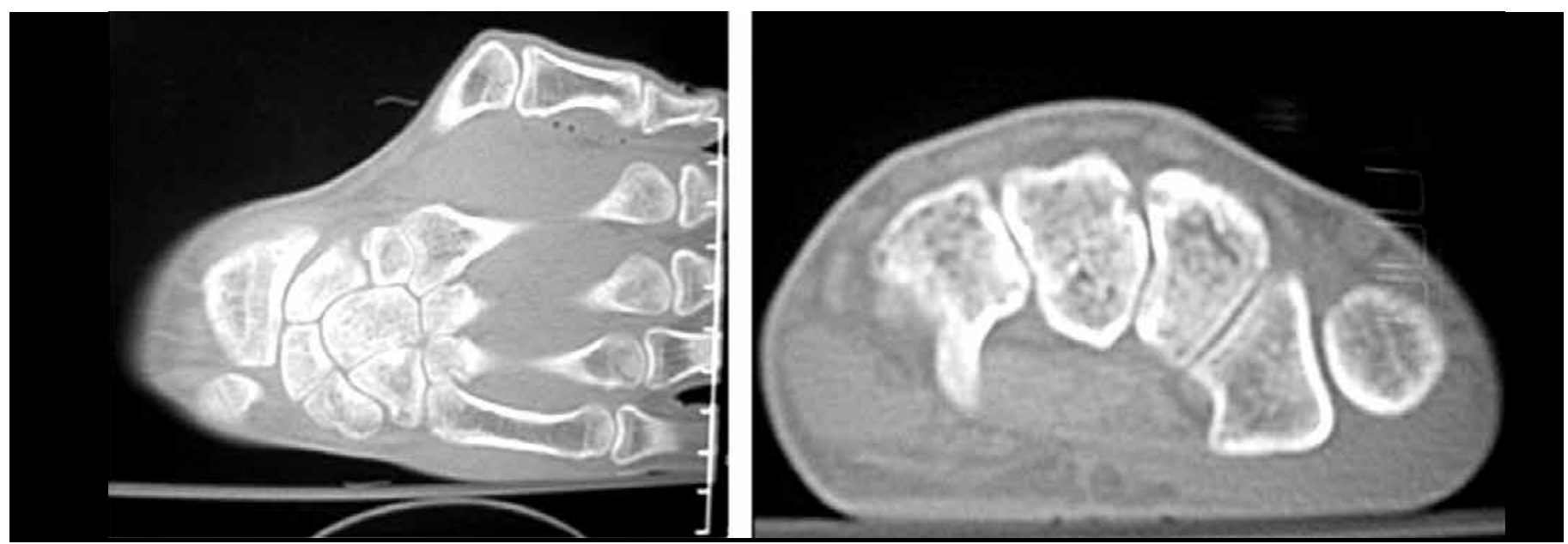

was completely free from symptoms, well adapted to daily life and working normally as the cashier in a gasoline station.

A radiograph showed that complete consolidation and incorporation of the graft into the focus of the pseudarthrosis had been achieved, and this was confirmed by means of computed tomography, which showed bone trabeculation and absence of displacement of the scaphoid tubercle (Figures 3 and 4).

\section{DISCUSSION}

Pseudarthrosis is the most common complication of scaphoid fractures and its important comes from the fact that it compromises a relatively young and economically productive population.

The present case is rare because of the occurrence of a fracture in an immature skeleton and because of the evolution to pseudarthrosis of the distal center,

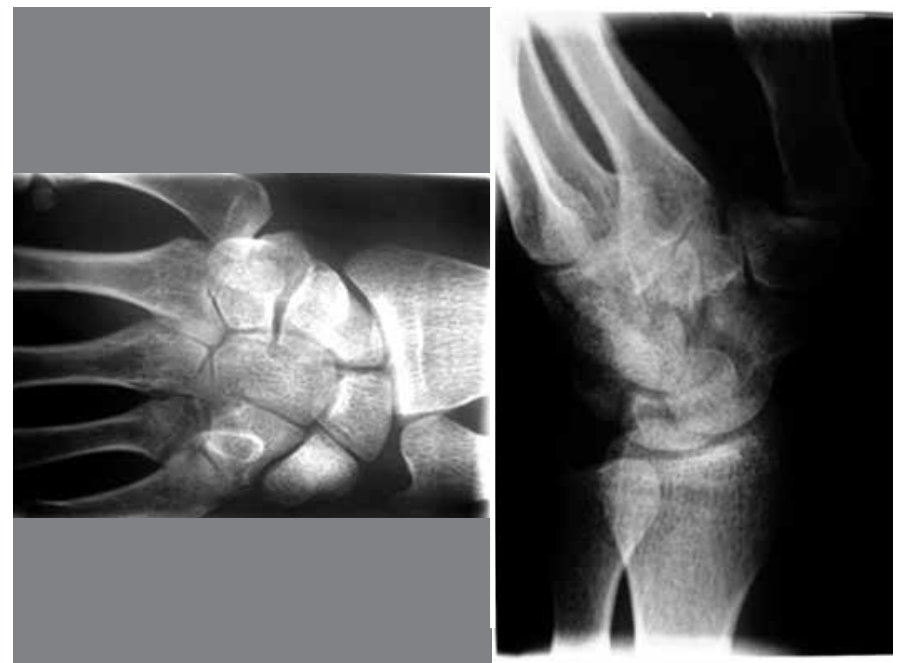

Figure 3 - Bone consolidation, four years after the operation. Note that the growth plates on the distal radius and ulna have now closed.

Figure 4 - Bone consolidation confirmed by means of computed tomography. 
which is a bone region that is richly vascularized ${ }^{(1-3)}$. With regard to epidemiology, the patient's age at the time of the fracture (14 years) and the site of the fracture (distal center, which is more frequent in immature skeletons) are in conformity with the literature ${ }^{(3)}$.

The real incidence of pseudarthrosis of the scaphoid is unknown, since there are many people who fracture this bone, do not have it treated develop asymptomatic pseudarthrosis and are not included in the "statistics"(5). The scarcity of cases in the literature makes it possible to speculate. We believe that the non-consolidation in the patient of the present report may have occurred because of his non-adherence to the initial treatment for the fracture, with removal of the immobilization ${ }^{(5)}$.

If a diagnosis cannot be confirmed by means of routine radiography, scintigraphy with technetium $99 \mathrm{~m}$, computed tomography or magnetic resonance imaging may be performed in order to confirm it.

There is no consensus regarding whether surgical or conservative treatment is more indicated ${ }^{(3)}$. Although non-operative treatment has been recommended by some authors ${ }^{(3)}$, we decided to treat the pseudarthrosis surgically for the following reasons: the patient's noncollaborative profile, given that he might not tolerate the prolonged immobilization needed for conservative treatment; and the patient's age, considering that despite his immature skeleton, his adolescent period was coming to an end and he would soon be faced with the functional demands of young adulthood.

A vascularized bone graft was not used for fear that the length of the artery feeding it (recurrent branch of the radial artery, Mathoulin; or the 2,3 dorsal artery, Zaidemberg) might not be sufficient to reach the distal center of the scaphoid. It was decided to use a free graft from the iliac crest, as described by Matti and Russe ${ }^{(1,4)}$.

As recommended in the literature ${ }^{(3)}$, smooth Kirschner wires were used because of their efficacy and ease of removal on an outpatient basis. Herbert screws would have been an option, but not only are these technically more difficult to use, but also their placement gives rise to doubts about the late-stage repercussions relating to synthesis material that is left in an immature skeleton for a long time ${ }^{(3)}$.

The radiographic consolidation and the patient's subsequent asymptomatic state led to the belief that the treatment options were correct.

Pseudarthrosis of the distal center of the scaphoid in an immature skeleton is a rare entity of exceptional occurrence, which may lead surgeons to be unsure regarding the best therapeutic approach. Nonetheless, the recommended treatment was shown to be an effective option in this specific case.

\section{REFERENCES}

1. Amadio P, Moran S. Fractures of the carpal bones. In: Green's operative hand surgery. 5th ed. Philadelphia: Elsevier; 2005. p.711-44.

2. Seitz W, Papandrea R. Fraturas e luxações do punho. In: Bucholz RW, Heckman JD. Rockwood e Green fraturas em adultos. 5a. ed. São Paulo: Manole; 2006. p.749-66.

3. Graham T, Waters P. Fraturas e luxações da mão e do carpo. In: Beaty J, Kasser J.
Rockwood e Wilkins. Fraturas em crianças 3.ed. São Paulo: Manole; 2004. p.341-360.

4. Pardini A, Freitas A. Fraturas e luxações dos ossos do carpo. In: Traumatismos da mão. 3a. ed. Rio de Janeiro: Medsi, 2000. p.481-9.

5. Ramos MRF, Torrero V, Torrero AM, Gomes WJ, NE, Santos LAVM. Tratamento da pseudartrose do escafóide carpal pela técnica de Matti-Russe utilizando enxerto retirado do olecrânio. Rev Bras Ortop. 2000;35(5):151-6. 